\title{
A new Cretaceous family of enigmatic two-winged lacewings (Neuroptera)
}

\author{
Vladimir N. Makarkin ${ }^{1,2}$, Qiang Yang $^{1}$ and Dong Ren ${ }^{*}, 1$ \\ ${ }^{1}$ College of Life Sciences, Capital Normal University, Beijing, 100048, China. E-mail: rendong@mail.cnu.edu.cn \\ ${ }^{2}$ Institute of Biology and Soil Sciences, Far Eastern Branch of the Russian Academy of Sciences, Vladivostok, 690022, Russia. \\ E-mail: vnmakarkin@mail.ru
}

\begin{abstract}
Received 31 January 2012

Accepted 1 August 2012

Published 20 February 2013

\section{Key Words}

Dipteromantispidae

Mantispidiptera

Yixian Formation

China

Lacewings (Neuroptera) normally bear four well-developed wings. There are a few brachypterous, micropterous or apterous species, found in several extant families; this wing reduction is usually associated with flightlessness. The only documented fossil neuropteran with reduced hind wings (modified to small haltere-like structures) is the enigmatic minute genus Mantispidiptera Grimaldi from the Late Cretaceous amber of New Jersey. In this paper, we report a new genus and species from the Early Cretaceous Yixian Formation of China (Dipteromantispa brevisubcosta n. gen. et n. sp.) resembling Mantispidiptera. We place these two genera in the new family Dipteromantispidae, n. fam. They bear well-developed forewings with reduced venation, and hind wings that are extremely modified as small structures resembling the halteres of Diptera. Dipteromantispidae $n$. fam. might be specialized descendants of some early Berothidae or of stem group Mantispidae + Berothidae. We presume that dipteromantispids were active fliers. This is a remarkable example of parallel evolution of wing structures in this neuropteran family and Diptera.
\end{abstract}

\section{Introduction}

Insects of the order Neuroptera usually bear four welldeveloped wings. However, there are a few brachypterous, micropterous or apterous species, found in several extant families (see a short review below). Grimaldi (2000) described the enigmatic fossil neuropteran genus Mantispidiptera Grimaldi and its two minute species M. enigmatica Grimaldi and M. henryi Grimaldi (forewings $2.63-3.12 \mathrm{~mm}$ long) from the Late Cretaceous (Turonian) amber of New Jersey (USA). This genus is noteworthy for its specialized forewing venation and hind wings reduced to small structures resembling the halteres of Diptera. He (and subsequent authors) associated it with the family Mantispidae, due to the presence of raptorial forelegs and forewing venation, which distantly resembles that of the mantispid subfamily Symphrasinae (Grimaldi 2000; Grimaldi \& Engel 2005; Aspöck \& Aspöck 2007; Engel \& Grimaldi 2007). However, Wedmann and Makarkin (2007, p. 709) stated the opinion that "the systematic position of this enigmatic genus remains unclear, but it most probably does not belong to Mantispidae", by its lack of significant mantispid synapomorphies. Engel \& Grimaldi (2008, p. 86) reinstated the genus within the family, explaining that it is "highly autapomorphic, with several apomorphies likely the result of miniaturization."

In this paper, we describe a new genus from the Early Cretaceous Yixian Formation of north-eastern China, which resembles Mantispidiptera but is much larger, yet its forewing venation is even further reduced. The reduced venation in this larger genus supports the suspicion of Wedmann and Makarkin (2007) that these character states are not explained by minute size, and that its character states that resemble those of the Mantispidae likely only superficially do so, and constitute insufficient reason to place it in that family. These genera are clearly closely related, together forming a supergeneric taxon, which we herein describe as the new family Dipteromantispidae n. fam., and discuss its relationship within the Neuroptera. We presume that they were active fliers.

\footnotetext{
* Corresponding author
} 


\section{Material and methods}

The new genus and species are based upon a single specimen, collected at the Huangbanjigou locality, situated approximately $21 \mathrm{~km}$ south of Beipiao, western Liaoning Province, China. These deposits belong to the Jianshangou Member (Bed) of the lower Yixian Formation (Wang \& Zhou 2008), which are considered to be of late Barremian age, $26.1 \pm 1.7-124.6 \pm 0.1 \mathrm{Ma}$ (Swisher et al. 1999, 2002; Wang et al. 2001b; Chen et al. 2004; Yang et al. 2007). The upper-most beds of the Huangbanjigou locality are considered early Aptian, $123.3 \pm 0.5-$ $122.8 \pm 1.6 \mathrm{Ma}$ (Wang et al. 2001a; Yang et al. 2007). The neuropteran assemblage of this locality is analysed by Makarkin et al. (2012). The specimen is housed in the Key Laboratory of Insect Evolution \& Environmental Changes, College of Life Sciences, Capital Normal University, Beijing, China (Prof. Ren Dong, curator). Photographs were taken using a Nikon Digital Camera DXM1200C attached to a Leica MZ12.5 stereomicroscope. The line drawings were prepared with CoralDraw 12 graphics software and Adobe Photoshop CS2.

\section{Terminology and abbreviations}

We follow the general body terminology of Snodgrass (1935), the female terminalia terminology of Aspöck \& Aspöck (2008), and the traditional (sensu Wootton 2003) venational terminology of Comstock (1918) as recently amended by Oswald (1993) and Archibald \& Makarkin (2006). Crossveins are designated by the longitudinal veins which they connect and numbered in sequence from the wing base, e.g., 1icu, the most proximal intracubital crossvein (i.e., between $\mathrm{CuA}$ and $\mathrm{CuP}$ ); $2 \mathrm{icu}$, the intracubital crossvein located distal to $1 \mathrm{icu} ; 1 \mathrm{r}-\mathrm{m}$, the most proximal crossvein between $\mathrm{R}$ (or Rs) and $\mathrm{M} ; 2 \mathrm{r}-\mathrm{m}$, the crossvein between $\mathrm{R}$ (or Rs) and $\mathrm{M}$ located distal to $1 \mathrm{r}-\mathrm{m}$.

Wing vein abbreviations used are as follows: Sc, subcosta; $\mathrm{R}$, radius; $\mathrm{R} 1$, first branch of R; Rs, radial sector; R1, most proximal branch of Rs; M, media; MA, media anterior; MP, media posterior; $\mathrm{Cu}$, cubitus; $\mathrm{CuA}$, cubitus anterior; $\mathrm{CuP}$, cubitus posterior; $1 \mathrm{~A}$, first anal vein.

\section{Systematic Paleontology}

\section{Order Neuroptera Linnaeus, 1758 Family Dipteromantispidae n. fam.}

Type genus. Dipteromantispa $\mathrm{n}$. gen.

Diagnosis. Small to minute mantispid-like neuropterans (forewing 2.6-7.9 mm long). Prothorax short, not tubular; forelegs raptorial, articulated to prothorax posteriorly; profemur armed with two-three rows of short denticles. Forewing venation strongly reduced, with small number of crossveins; trichosors, nygmata, pterostigma absent; subcostal veinlets simple; Sc relatively short, widely separated distally from R1; Rs originating very far from wing base, with few branches; $\mathrm{M}, \mathrm{Cu}$ forked near wing base. Hind wing strongly reduced, modified to haltere-like structure.

Genera included. Dipteromantispa n. gen., Mantispidiptera Grimaldi, 2000. Stratigraphic and geographic range. Yixian Formation (Early Cretaceous, Barremian) of Liaoning (China), and the Raritan Formation (Late Cretaceous, Turonian) of New Jersey (USA).

\section{Dipteromantispa n. gen.}

Derivation of name. From Diptera and Mantispa (a genus-group name), in reference to its two dipteran-like wings, yet mantispid-like appearance of this neuropteran. Gender: feminine.

Type and only species: Dipteromantispa brevisubcosta $\mathrm{n}$. gen. et n. sp. Diagnosis. Larger than Mantispidiptera, forewing about $8 \mathrm{~mm}$ long [Mantispidiptera: forewing 2.6-3.1 mm long]; in forewing, Sc very short, joining margin at approximately mid-wing [Mantispidiptera: Sc longer, joining margin at approximately distal one-third wing length]; MP forked once [Mantispidiptera: forked twice]; $\mathrm{CuA}$ simple [Mantispidiptera: deeply forked].

\section{Dipteromantispa brevisubcosta $\mathbf{n}$. sp.}

Figures $1-3 \mathrm{~A}, \mathrm{~B}$

Derivation of name. From the Latin brevis, short, and subcosta (noun), subcostal vein, in reference to its short $\mathrm{Sc}$

Holotype. CNU-NEU-LB2011013, a nearly complete, quite well-preserved female specimen in ventral aspect, is housed in the Key Laboratory of Insect Evolution \& Environmental Changes, College of Life Sciences, Capital Normal University, Beijing, China.

Type locality and horizon. Huangbanjigou, Beipiao City, Liaoning Province, China; Yixian Formation, Early Cretaceous.

Description. Head nearly as wide as prothorax; posterocular lobe expanded. Antennae widely spaced, long; scapus short, length approximately equal to width; distinctly larger than other segments; pedicellus short, only slightly larger that first flagellomere; flagellum with about 40 flagellomeres.

Thorax preserved in ventral aspect. Boundaries between prothorax, mesothorax and metathorax indistinct. Prothorax rather short, narrowed, rounded anteriorly. Anterior lateral cervical sclerite large, pear-shaped, with very broad posterior rounded part, and short, narrow anterior narrower part of 'pear' (poorly visible); well extending beyond sides of prothorax; with long, quite dense, laterally directed hairs. Posterior lateral cervical sclerite, episternum (= propleuron) hard to discriminate; this united structure elongate, with long, quite dense, directed laterally hairs in anterior part. Basisternum small, narrow, with short median longitudinal ridge; rather strongly sclerotized area present anterior to basisternum; narrow precoxal bridge connecting strongly sclerotized area anterior to basisternum and episternum present. Furcasternum indistinct, weakly sclerotized.

Forelegs raptorial; procoxa elongate, stout, covered with dense, rather short hairs; protrochanter rather small; profemur broad, half-oval in lateral view, covered with fine short hairs; armed with one-two (proximally, distally) to three (medially) short denticles; tibiae, tarsi not preserved. Mesothorax largest segment of thorax, weakly sclerotized ventrally. Middle legs not preserved. Metathorax smaller than mesothorax, weakly sclerotized ventrally. Hind legs: metacoxa large, heavily sclerotized; metatrochanter apparently transverse; metafemur elongate, slender (incompletely preserved).

Abdomen. Boundaries between segments not distinct. Gonocoxites of 7 th segment paired, with finger-like process (alternatively, 7th or 8th tergite expanded to ventral side, terminated with strong processes). Gonocoxites of 9th segment (= gonopophyses laterales) ovoid (in ventral view), with small anterior projection (?hypocaudae). Gonostyli not detected, probably absent.

Forewing $7.9 \mathrm{~mm}$ long, ovate in shape, without maculation. Costal space strongly dilated at its middle length, narrowed basally, distally. Sc very short, enter- 


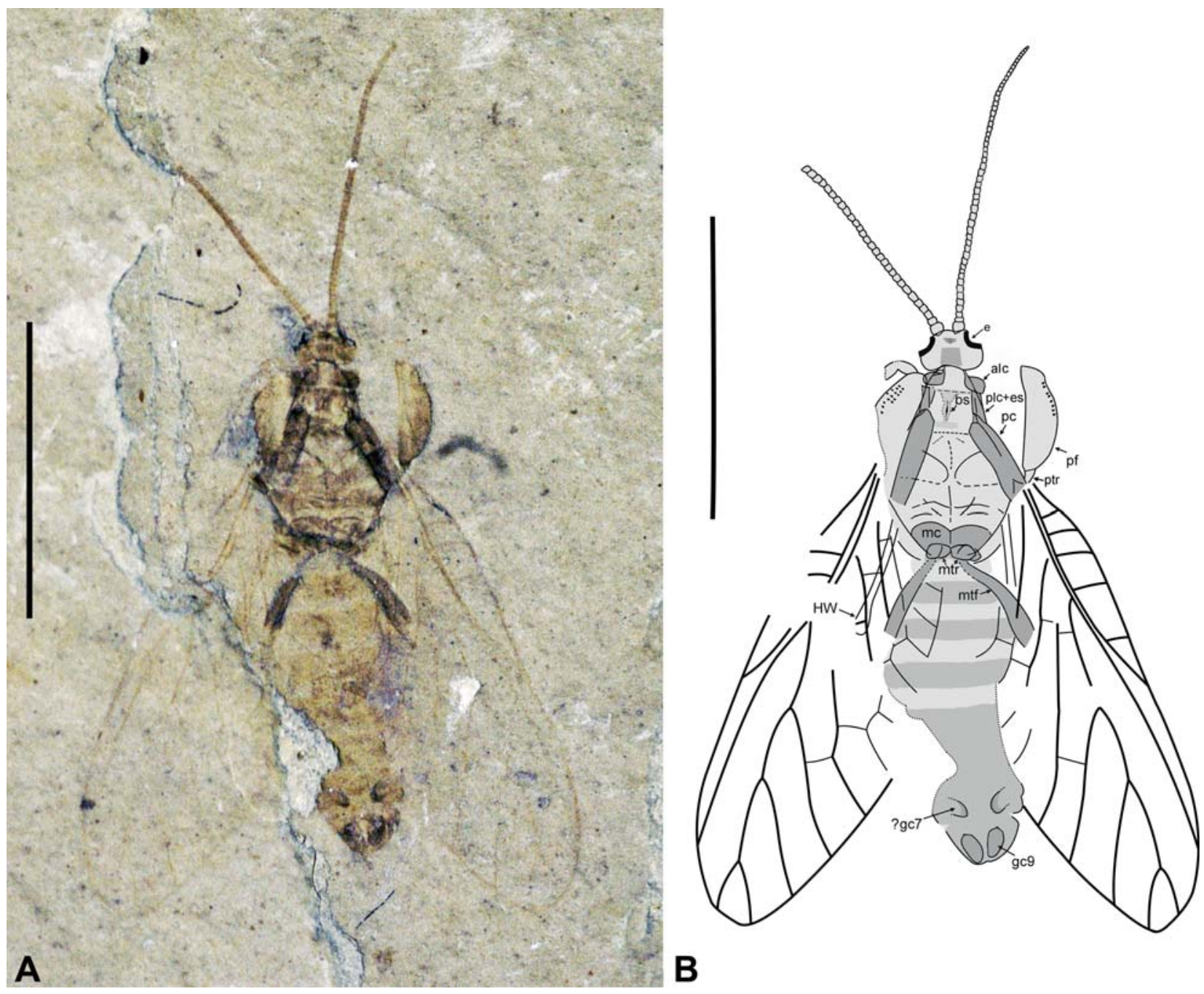

Figure 1. Dipteromantispa brevisubcosta n. gen. n. sp. from Liaoning Province, China (holotype CNU-NEU-LB2011013). A. Photograph (ventral view, dry); B. Drawing (body pattern slightly schematized). alc - anterior lateral cervical sclerite; bs - basisternum; e - eye; es - episternum; gc7 - gonocoxites of the 7th segment; gc9 - gonocoxites of the 9th segment; HW - hind wing; mc - metacoxa; mtf - metafemur; mtr - metatrochanter; pc - procoxa; pf - profemur; plc - posterior lateral cervical sclerite; ptr - protrochanter. Scale bar, $5 \mathrm{~mm}$.

ing margin approximately at wing mid-point. Five preserved subcostal veinlets: simple, straight, widely spaced. R1 entering margin before wing apex; its veinlets not detected. Subcostal space narrow proximally, broadens towards termination of Sc; distinct crossveins not detected. Pterostigma absent. R1 space very broad, crossveins not detected. Rs originating very far from wing base, approximately at one-third of wing length. Rs with three simple, widely spaced branches. Two crossveins between R, M systems: basal 1r-m, distal 2r$\mathrm{m}$. M basally fused with $\mathrm{R}$ for long distance. Fork of $\mathrm{M}$ poorly preserved, probably near apparent origin of M. Two intramedian crossveins (1im, 2im) located proximad crossveins 1r-m, 2r-m respectively. Probably two crossveins between $\mathrm{M}, \mathrm{Cu}$ systems. MA simple, entering margin after wing mid-point. MP rather deeply forked. $\mathrm{Cu}$ probably forked near wing base (fork not preserved). Two intracubital crossveins. CuA simple, rather short. $\mathrm{CuP}$ parallel to $\mathrm{CuA}$, probably with one branch. Possible 1A fragmentarily preserved.
Hind wings poorly preserved in general, but clearly modified to haltere-like structures, about $1.9 \mathrm{~mm}$ long. Stem of haltere-like structure about $0.2 \mathrm{~mm}$ wide; its head about $0.3 \mathrm{~mm}$ wide. No venation evident.

\section{Discussion}

\section{Distinctive features of Dipteromantispidae}

Lateral cervical sclerites. The presence of two pairs of cervical sclerites is a potential apomorphy of Neuroptera (occurring also in Zoraptera, Psocoptera, and Diptera, presumably convergently) (Friedrich \& Beutel 2010), and their derivation from the preepisternum is considered an autapomorphy of the order (Beutel et al. 2010). Pear-shaped lateral cervical sclerites is the plesiomorphic condition in Neuroptera (Friedrich \& Beutel 2010). The anterior lateral cervical sclerite (alc) in Dipteromantispa $\mathrm{n}$. gen. is indeed slightly pear-shaped, with 

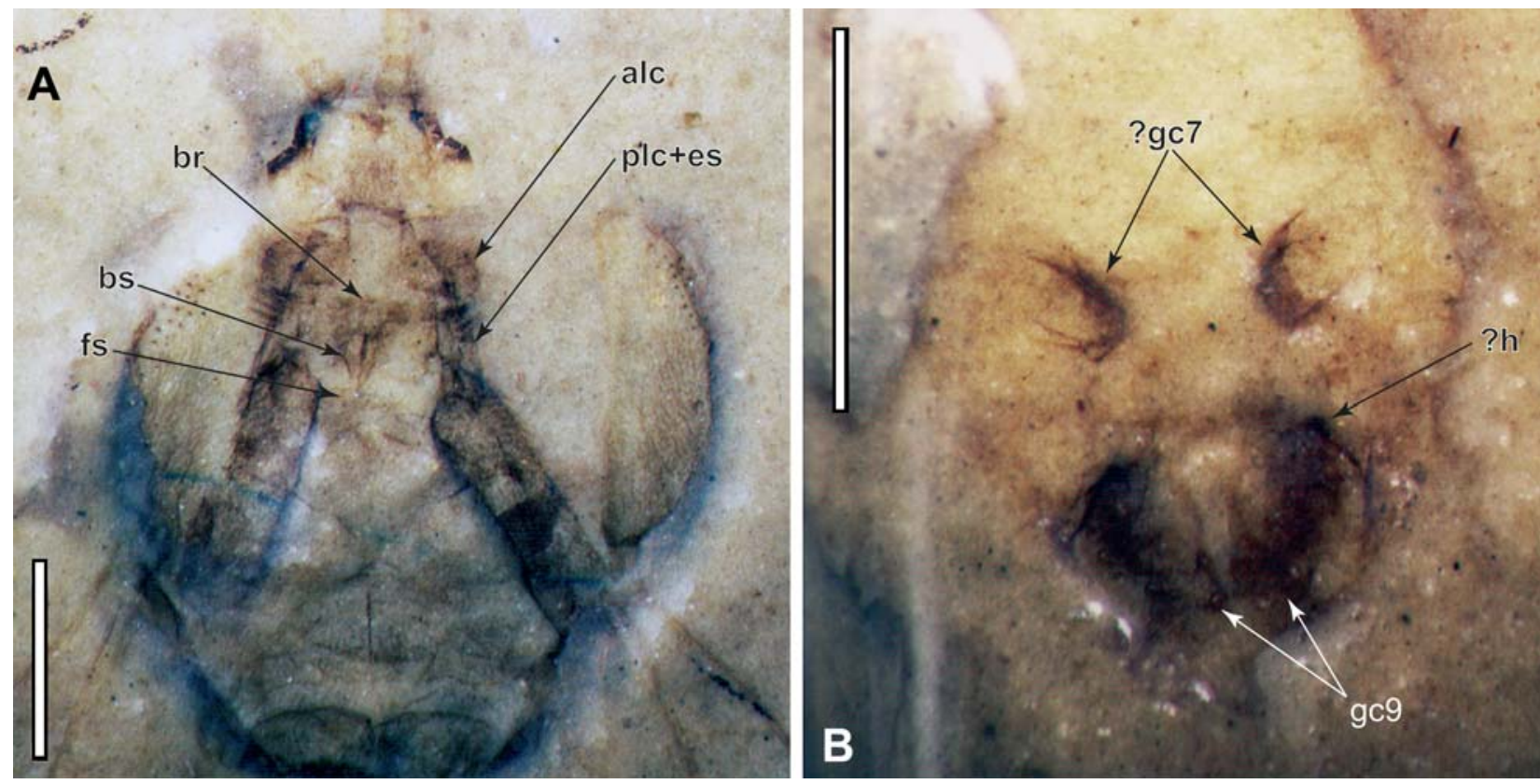

Figure 2. Dipteromantispa brevisubcosta n. gen. n. sp. from Liaoning Province, China (holotype CNU-NEU-LB2011013). A. Head, prothorax and mesothorax (ventral view); B. Apex of abdomen (ventral view). Both photographed in ethanol; alc - anterior lateral cervical sclerite; br - precoxal bridge; bs - basisternum; es - episternum; fs - furcasternum; gc7 - gonocoxites of the 7th segment; gc9 - gonocoxites of the 9th segment; $\mathbf{h}$ - hypocaudae; plc - posterior lateral cervical sclerite. Scale bar, $1 \mathrm{~mm}$.

a very broad posterior rounded part, and a short, narrow, anterior narrower part of the 'pear' (poorly visible in this specimen). This is similar to the alc of the berothid (rhachiberothine) genus Hoelzeliella Aspöck \& Aspöck (Aspöck \& Aspöck 1997, fig. 33) and of Mantispa Illiger, which belongs to an advanced subfamily of Mantispidae (Crampton 1926, fig. 52). However, the alc is much longer and more slender in another, more primitive mantispid genus, Plega Navás (Symphrasinae)
(Matsuda 1970, fig. 118C). The same situation is found in some Chrysopidae: alc is a narrow slender 'pear' in the more primitive subfamily Nothochrysinae, and a rounded 'pear' in the more advanced subfamily Chrysopinae (see Crampton 1926, fig. 51; Adams 1967, figs 35-37). The posterior lateral cervical sclerite ( $p l c)$ is usually small in extant taxa (e.g., Crampton 1926, fig. 51, labelled 'postcervicale'), and hardly distinguishable in fossils. For example, it was not reported in
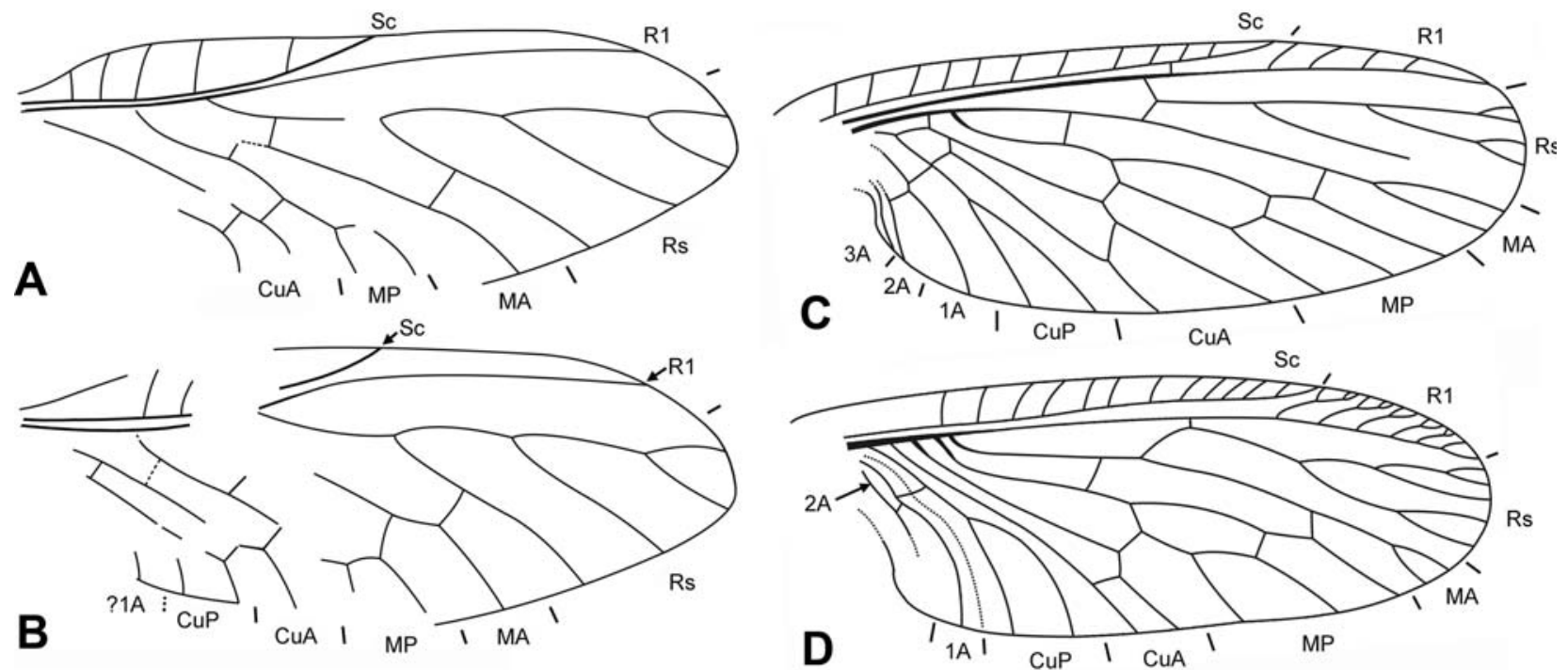

Figure 3. Forewing venation of Dipteromantispidae n. fam. A. Left forewing of Dipteromantispa brevisubcosta n. gen. n. sp.; B. Right forewing of D. brevisubcosta $\mathrm{n}$. gen. n. sp. (converted to right aspect for ease of comparison); C. Mantispidiptera enigmatica Grimaldi; D. M. henryi Grimaldi (re-drawn from Grimaldi 2000, fig. 14, vein labelling is ours). Scale bar, $5 \mathrm{~mm}$ (for A and B, scale not provided by Grimaldi 2000). 
the Eocene Archaeochrysa creedi (Carpenter) (see Adams 1967, fig. 47). Therefore, the structure labelled 'plc + es' $[$ plc + episternum] in Figs 1B and 2A probably represents for the most part the episternum.

Basisternum. The actual shape of the basisternum in Dipteromantispa n. gen. is hard to determine. Examination of the specimen wetted with ethanol indicates three possibilities: (1) it is small and narrow (its boundary is rather distinct), with a median longitudinal ridge; a dark area anterior to the basisternum in this case is simply fuscous membrane, including an area of the precoxal bridge (see below); (2) the basisternum is small and narrow with a median longitudinal ridge; a dark area anterior to the basisternum (including an area of the precoxal bridge) is a secondary sclerotized membrane; (3) the basisternum is larger comprising whole dark area (its boundary is not distinct; see Fig. 2A), with a median longitudinal ridge in posterior half; the precoxal bridge is in this case homologous with that of Mantispa. In our opinion, the second possibility is most likely.

A small basisternum is the plesiomorphic condition in Neuroptera, occurring often in the order (Matsuda 1970; Friedrich \& Beutel 2010). In Chrysopidae, the basisternum is small in the more primitive Nothochrysinae, and larger in the more advanced Chrysopinae (see Crampton 1926, fig. 51; Adams 1967, figs 35-37).

Precoxal bridge. A weakly sclerotized precoxal bridge connecting the basisternum (or a sclerotized membrane, see above) and episternum (propleuron) anterior to the procoxae appears to be present in Dipteromantispa n. gen. Within the Neuroptera, the precoxal bridge has only been reported in Mantispa, but is probably more strongly sclerotized there (see Crampton 1926, fig. 52). In general, it is present in many non-endopterygote insects, "but is unlikely to be a groundplan feature of Endopterygota" (Friedrich \& Beutel 2010, p. 17). The possible presence of a precoxal bridge in Dipteromantispidae is most probably secondary, and therefore autapomorphic, not homologous with that of Mantispa.

Profemur. The structure and arrangement of the profemoral teeth of Dipteromantispidae are most similar to those of the extant berothid (Rhachiberothinae) genus Hoelzeliella Aspöck \& Aspöck (Aspöck \& Aspöck 1997, fig. 33), the mantispid (Symphrasinae) genus Trichoscelia Westwood (Penny 1982, fig. 10; Hoffman 2002, fig. 539), and the Mesozoic mantispid subfamily Mesomantispinae (V. Makarkin, personal observation) in the absence of long spines and in the presence of only small 'denticles' in two-three rows (more than three in some Mesomantispinae). In other Mantispidae and Rhachiberothinae, at least one long spine is present (often more than one). In the fossil berothid subfamilies Paraberothinae and Mesithoninae, all of the numerous spines are usually more or less long (see Engel 2004; Nel et al. 2005; McKellar \& Engel 2009; Petrulevicius et al. 2010).

Gonocoxites of 7th abdominal segment. The nature of the pair of finger-like structures at the ventral side of the abdomen is hard to identify (Fig. 2B). They appear to be ventral appendages of the 7 th or 8 th segments, most resembling the paired posterior processes of the 7th sternite of some species of the mantispid genus Theristria Gerstaecker (Lambkin 1986, fig. 36), the gonocoxites of the 7th abdominal segment of Hoelzeliella (Aspöck \& Aspöck 1997, fig. 33), or the gonocoxites of the 8 th abdominal segment (subgenitale) of Rhachiberotha Tjeder (Tjeder 1959, figs 243D, E). We interpret these structures as the 7th gonocoxites, as they are located distant enough from the 9th gonocoxites; moreover, the 8th gonocoxites (subgenitale) in extant taxa are usually not finger-like. It is also possible (but very unlikely) that these structures may be terminal parts of the pseudohypocaudae of the 9th tergite, like those of Berothidae (e.g., Aspöck \& Aspöck 1997, fig. 33). In any case, the presence of this pair of finger-like structures shows that the Dipteromantispidae appears to have a close relationship with Berothidae and/or Mantispidae.

Gonocoxites of 9th abdominal segment. The ventral morphology of the 9th gonocoxites (ovoid, reniform) is typical for the majority of extant Neuroptera taxa. Female gonostyli are absent in all Mantispidae and Berothidae (including Rhachiberothinae), and many other families. Their presence in Osmylidae, Ithonidae, Psychopsidae, and Hemerobiidae is confidently the plesiomorphic condition.

The small anterior projection of the 9th gonocoxites resembles the short hypocaudae of Berothidae (including Rhachiberothinae) (e.g., Aspöck \& Aspöck 1984, figs 14,39 ; 1997, fig. 40). The presence of the hypocaudae is an apomorphic condition, and occurs only in Berothidae (Aspöck 1986; Aspöck \& Nemeschkal 1998).

Forewing venation. The forewing of Dipteromantispa n. gen. (about $8 \mathrm{~mm}$ long) has very reduced (simplified) venation, almost like that of Coniopterygidae, a family of the smallest neuropterans. Almost all longitudinal veins and branches are simple, lacking branches. The forewing of Mantispidiptera differs from that of Dipteromantispa n. gen. by slightly more complete venation, i.e., more closely spaced subcostal veinlets; the presence of the veinlets of R1; the distal forks of MA, Rs and its branches; the additional deep fork of MP and $\mathrm{CuA}$. The number and arrangement of crossveins (confidently detected) are almost identical in these two genera, although the forewing of Dipteromantispa n. gen. is nearly three times the size of that of Mantispidiptera.

The venation of the two species of Mantispidiptera is similar in general, but $\mathrm{M}$ and $\mathrm{Cu}$ are basally separated from $\mathrm{R}$ in $M$. enigmatica, a plesiomorphic condition, and fused with $\mathrm{R}$ for the considerable distance in $M$. henryi, an apomorphic condition. Based on the same arrangement of the crossveins in these two species, we interpret the venation of $M$. henryi differently from Grimaldi (2000): his 'Rs' is our Rs and MA; his ' $M$ ' is our MP (Figs 3C, D). 
The venation of Dipteromantispidae can in principle be derived from that of different families by simplification, but this seems most likely from some primitive Mantispidae (like Symphrasinae) and Berothidae (like Rhachiberothinae) with Sc and R1 not fused distally.

\section{Systematic position of Dipteromantispidae}

This family undoubtedly belongs to Neuroptera by the reduced cerci (as in all Neuropterida), small prothoracic basisternum (large in Raphidioptera and Megaloptera), and the probable presence of two pairs of cervical sclerites (the latter character is not clearly visible, see above) (Kristensen 1991; Friedrich \& Beutel 2010). Within the Neuroptera, the Dipteromantispidae n. fam. is obviously a specialised taxon, with secondarily simplified forewing venation, and strongly modified hind wings. From the above analysis, we believe that the body structures and the raptorial forelegs of Dipteromantispidae $\mathrm{n}$. fam. clearly indicate its position near Berothidae and Mantispidae (we consider Berothidae as including Rhachiberothinae). These families are generally thought to be sister taxa (e.g., Aspöck et al. 2001; Winterton et al. 2010), but Mantispidiptera and Dipteromantispa $\mathrm{n}$. gen. may not be assigned to them.

As mentioned above, Mantispidiptera has been previously assigned to Mantispidae. The fossil record of Mantispidae includes 12 described species that range from the Early Jurassic to the Middle Miocene (Cockerel 1921; Panfilov 1980; Nel 1989; Makarkin 1990, 1997; Ohl 2004; Poinar 2006; Engel \& Grimaldi 2007; Wedmann \& Makarkin 2007; Poinar \& Buckley 2011). A mantispid larva is known from the Late Eocene Baltic amber (Ohl 2011). In Jurassic and Early Cretaceous specimens, mantispid bodies are usually well-preserved, and their features are typical for the family, including the structure of the prothorax and forelegs (V. Makarkin, personal observation; see also Makarkin et al. 2012, fig. 3A).

The principal autapomorphy of Mantispidae (the pronotum posterior to the forelegs is prolonged forming a tube in the vast majority of species) is not characteristic of Dipteromantispidae n. fam. In general, its prothorax is dissimilar to that of Mantispidae, but is similar to that of more generalized taxa (e.g., Berothidae, Sisyridae, Nevrorthidae). Forewing venation is strongly derived in Dipteromantispidae n. fam., but that of Mantispidiptera enigmatica maintain some plesiomorphic features, e.g., $\mathrm{M}$ and $\mathrm{R}$ are basally separate. In this respect its venation differs from that of Mantispidae, in which $\mathrm{M}$ is always basally fused with $\mathrm{R}$ for a considerable distance. This is unlikely to represent a reversion from joined to separated $\mathrm{M}$ and $\mathrm{R}$; such a case has not been supposed in any neuropteran lineages. Therefore, by these two characters, these two genera cannot be assigned to the Mantispidae with any confidence.

The body morphology of the Dipteromantispidae female (i.e., Dipteromantispa n. gen.) is most similar to that of the berothid (rhachiberothine) genus Hoelzeliella by the posterior articulation of the forelegs to the prothorax, the structure of profemur (no long spines), prothorax morphology (rounded alc), and the apex of the abdomen (the presumably paired gc7 and small hypocaudae). But, this fossil lacks well-developed pseudohypocaudae (present in Hoelzeliella and other Rhachiberothinae). The length of the scapus in Dipteromantispidae n. fam. (nearly as long as wide) is plesiomorphic in Neuroptera. In Berothidae, the scapus is usually long to very long, rarely (Rhachiberothinae) moderately elongate (twice longer than wide). It is possible that Dipteromantispidae are specialized descendants of early Berothidae in which case Dipteromantispidae n. fam. would be considered a subfamily of Berothidae (however, available material does not provide sufficient evidence of this).

The Berothidae is known since at least the Middle Jurassic (see a checklist in Makarkin et al. 2011). All species of the berothid subfamilies Rhachiberothinae and Paraberothinae and at least one species of Mesithoninae have raptorial forelegs. The Mesithoninae occur in the Late Jurassic to Early Cretaceous (Panfilov 1980; Ren \& Guo 1996; Makarkin 1999) and the Paraberothinae only in the Cretaceous (see a review of Makarkin \& Kupryjanowicz 2010; Petrulevicius et al. 2010). The reported fossil record of the Rhachiberothinae is restricted to the Cenozoic (Whalley 1983; Makarkin \& Kupryjanowicz 2010).

It is also possible that Dipteromantispidae n. fam. represents specialized descendants of stem group Mantispidae + Berothidae, as indicated by the presence of some plesiomorphic conditions (forelegs articulated to the prothorax posteriorly; scapus short; generalized prothorax; forewing $\mathrm{M}$ and $\mathrm{R}$ are basally not fused, found in one species).

\section{Wing reduction in extant Neuroptera}

Within the order Neuroptera, species with brachypterous, micropterous or apterous wings are known in the families Coniopterygidae, Hemerobiidae, Ithonidae, Berothidae, Dilaridae, and Nemopteridae (Oswald 1996; Pantaleoni \& Letardi 1996). This reduction of wings occurs more or less often in Coniopterygidae and Hemerobiidae, and is very rare in other families. Among Coniopterygidae, the hind wings in most species of Conwentzia Enderlein are brachypterous in both sexes, and retain elements of venation. In some species of Helicoconis Enderlein both wings are brachypterous or entirely reduced only in the female (Meinander 1972), except for one high altitude species collected under moss on stones at an elevation of $4183 \mathrm{~m}$ on Mount Ruwenzori, where both wings are micropterous in the male (the female is unknown) (Kimmins 1950). In one species of Coniopteryx Curtis the female possesses brachypterous hind wings (Meinander 1972). Among Hemerobiidae, reduction of wings is known in both sexes, and occurs mainly in species inhabiting 
oceanic islands (several species of Micromus Rambur from the Hawaiian Archipelago; two species of Conchopterella Handschin from the Juan Fernandez Islands) and at high elevation in mountains (two species of Nusalala Navás from Costa Rica and Columbia at an elevation of 2620-3350 m and $3800 \mathrm{~m}$ respectively) (Zimmerman 1939, 1946, 1957; Handschin 1955; Penny \& Strum 1984; Oswald 1996). The only exception is the dimorphic Psectra diptera Burmeister, widely distributed in the Holarctic region, which includes macropterous and micropterous specimens (with hind wings fully developed or strongly reduced respectively) (e.g., see MacLeod 1960). The brachyptery of Micromus usingeri (Zimmermann) is associated mainly with cool, dry environments at high elevations in the Island of Hawaii (Tauber et al. 2007). Both pairs of wings are absent in the female of Adamsiana curoei Penny (Ithonidae) from Honduras; the male is fully winged (Penny 1996). The flightless female of Dilar parthenopaeus Costa (Dilaridae) from Italy has brachypterous wings (Pantaleoni \& Letardi 1996). The female of the berothid species Trichoma gracilipenne Tillyard from Australia has slightly brachypterous wings; the males are fully winged (Aspock \& Aspock 1985).

Reduction of wings in extant Neuroptera is usually associated with flightlessness (see Oswald 1996), except for Coniopteryx species, which have brachypterous hind wings only (Meinander 1972). In general, two main reasons may probably cause wing reduction: extreme conditions such as cool climate or winds at high elevation, and lack of need for flight in females, whose wings (only hind or both) may be reduced, with the males fully-winged.

\section{Reduction of hind wings in Dipteromantispidae}

The strong reduction of hind wings in fossil Neuroptera is only documented in Dipteromantispidae n. fam. Judging from the structure of the dipteromantispid forewings, we can reasonably assume that they were active fliers, as their forewings lack a secondary thickening of the membrane, brachyptery, and other features of flightlessness (Oswald 1996). In this respect, the wings of Dipteromantispidae n. fam. (especially Dipteromantispa n. gen.) appear functionally more similar to those of Diptera than of other Neuroptera, by forewing shape, strong reduction of the venation, and modification of hind wings to haltere-like structures. In Dipteromantis$p a$ n. gen., the haltere-like structures are not clearly visible due to poor preservation, but they are seen to be well developed in Mantispidiptera. It is believed that the halteres play an important role in flight stabilization in Diptera (Pringle 1948; Dickson et al. 2008; Fox \& Daniel 2008), an order with some of the strongest flying insects. No other insects are known to possess such hind wing haltere-like structures, although the forewings of males in the order Strepsiptera are transformed into pseudohalteres, morphologically similar to the hal- teres of Diptera (Pohl et al. 2005). We find that the reduction of hind wings in the majority of extant species of Neuroptera and in Dipteromantispidae n. fam. could be generated by various reasons. We can assume that in this family the reduction of hind wings and its transformation to the haltere-like structures might have been connected with a strengthening, not weakening of flight. Therefore, this is a remarkable example of parallel evolution of wing structures exhibited by Dipteromantispidae n. fam. and Diptera.

In general, extreme reduction of the hind wings with only the forewings used as functional flying organs occurs quite rarely in insects. The occurrence of this condition throughout the order Diptera is exceptional in this respect; however, single species and genera whose hind wings are reduced occur in almost every insect order of Pterygota. We know of only two other families outside of the Diptera where all species are two-winged (fully developed forewings and hind wings strongly reduced or entirely lost), the Late Permian families Permothemistidae (Megasecoptera) and Eukulojidae (Palaeodictyoptera). Other families in these two orders have four well-developed wings (Sinitshenkova 2002).

\section{Conclusions}

The genera Mantispidiptera and Dipteromantispa n. gen. form a monophyletic group based on the similar structure of their raptorial forelegs, similar forewing venation, and hind wings modified to haltere-like structures. This group cannot be confidently assigned to any known family. Therefore, we erect the new family Dipteromantispidae $\mathrm{n}$. fam. for these strongly specialized insects, whose hind wings have been modified as small structures resembling the halteres of Diptera. The study of future specimens is required to resolve some outstanding issues concerning its systematic position within the Neuroptera. Currently, two scenarios appear probable: Dipteromantispidae n. fam. might be specialized descendants of some early Berothidae, or of stem group Mantispidae + Berothidae. We assume that they were likely active fliers. This is a remarkable example of parallel evolution of these wing structures in the Dipteromantispidae n. fam. (Neuroptera) and Diptera.

\section{Acknowledgements}

We thank Dr. Bruce Archibald (Simon Fraser University, Burnaby, Canada) for attentive reading of the manuscript, comments and improvement of the English. We also thank the reviewers Catherine Tauber (Cornell University, Ithaca, USA) and Michael Ohl (Museum für Naturkunde, Berlin, Germany) for their helpful critical comments. This research is supported by the National Natural Science Foundation of China (Nos. 31230065, 41272006, 31071964), National Basic Research Program of China (973 Program) (2012CB821906), China Geological Survey (1212011120116) and Scientific Research Key Program KZ200910028005, and PHR Project of Beijing Municipal Commission of Education (20090509, 201107120). 


\section{References}

Adams, P. A. 1967. A review of the Mesochrysinae and Nothochrysinae (Neuroptera: Chrysopidae). - Bulletin of the Museum of Comparative Zoology 135: 215-238.

Archibald, S. B. \& Makarkin, V. N. 2006. Tertiary giant lacewings (Neuroptera: Polystoechotidae): revision and description of new taxa from western North America and Denmark. - Journal of Systematic Palaeontology 4: 119-155 [errata: 4: 307].

Aspöck, U. 1986. The present state of knowledge of the family Berothidae (Neuropteroidea: Planipennia). In Gepp, J., Aspöck, H. \& Hölzel, H. (eds). Recent Research in Neuropterology. Proceedings of the 2nd International Symposium on Neuropterology. Privately printed, Graz, Austria: pp. 87-101.

Aspöck, U. \& Aspöck, H. 1984. Die Berothiden Australiens I: Neue Spezies des Genus Stenobiella Tillyard (Neuropteroidea: Planipennia: Berothidae). - Zeitschrift der Arbeitsgemeinschaft Österreichischer Entomologen 36: 17-32.

Aspöck, U. \& Aspöck, H. 1985. Die Berothiden Australiens (und Neuseelands) II: Die Genera Trichoma Tillyard, Trichoberotha Handschin, Protobiella Tillyard und Austroberothella n. g. (Neuropteroidea: Planipennia: Berothidae). - Zeitschrift der Arbeitsgemeinschaft Österreichischer Entomologen 36 (for 1984): 65-85.

Aspöck, U. \& Aspöck, H. 1997. Studies on new and poorly-known Rhachiberothidae (Insecta: Neuroptera) from subsaharan Africa. Annalen des Naturhistorischen Museums in Wien 99B: 1-20.

Aspöck, U. \& Aspöck, H. 2007. Verbliebene Vielfalt vergangener Blüte. Zur Evolution, Phylogenie und Biodiversität der Neuropterida (Insecta: Endopterygota). - Denisia 20: 451-516.

Aspöck, U. \& Aspöck, H. 2008. Phylogenetic relevance of the genital sclerites of Neuropterida (Insecta: Holometabola). - Systematic Entomology 33: 97-127.

Aspöck, U. \& Nemeschkal, H. L. 1998. A cladistic analysis of the Berothidae (Neuroptera). - Acta Zoologica Fennica 209: 45-63.

Aspöck, U., Plant, J. D. \& Nemeschkal, H. L. 2001. Cladistic analysis of Neuroptera and their systematic position within Neuropterida (Insecta: Holometabola: Neuropterida: Neuroptera). - Systematic Entomology 26: 73-86.

Beutel, R. G., Zimmermann, D., Krauss, M., Randolf, S. \& Wipfler, B. 2010. Head morphology of Osmylus fulvicephalus (Osmylidae, Neuroptera) and its phylogenetic implications. - Organisms Diversity \& Evolution 10: 311-329.

Chen, S. W., Jin, C. Z., Zhang, Y. P., Zhang, L. D. \& Guo, S. Z. 2004. Discussion on the structural-volcanic activities and biological events during the Early Cretaceous in the Sihetun Area, Liaoning Province, China. - Tikhookeanskaya Geologiya 23 (3): 52-59.

Cockerell, T. D. A. 1921. Fossil arthropods in the British Museum, VI. Annals and Magazine of Natural History (ser. 9) 7: 453-480.

Comstock, J. H. 1918. The wings of Insects: An Exposition of the Uniform Terminology of the Wing-veins of insects and a Discussion of the More General Characteristics of the Wings of the Several Orders of Insects. Comstock Publishing Company, Ithaca.

Crampton, G. C. 1926. A comparison of the neck and prothoracic sclerites throughout the orders of insects from the standpoint of phylogeny. - Transactions of the American Entomological Society 52: $199-248$.

Dickson, W. B., Straw, A. D. \& Dickinson, M. H. 2008. Integrative model of Drosophila flight. - AIAA Journal 46: 2150-2164.

Engel, M. S. 2004. Thorny lacewings (Neuroptera: Rhachiberothidae) in Cretaceous Amber from Myanmar. - Journal of Systematic Palaeontology 2: 137-140.

Engel, M. S. \& Grimaldi, D. A. 2007. The Neuropterid fauna of Dominican and Mexican amber (Neuropterida: Megaloptera, Neuroptera). - American Museum Novitates 3587: 1-58.

Engel, M. S. \& Grimaldi, D. A. 2008. Diverse Neuropterida in Cretaceous amber, with particular reference to the paleofauna of Myanmar (Insecta). - Nova Supplementa Entomologica 20: 1-86.
Fox J. L. \& Daniel, T. L. 2008. A neural basis for gyroscopic force measurement in the halteres of Holorusia. - Journal of Comparative Physiology A194: 887-897.

Friedrich, F. \& Beutel, R. G. 2010. Goodbye Halteria? The thoracic morphology of Endopterygota (Insecta) and its phylogenetic implications. - Cladistics 26: 1-34.

Grimaldi, D. A. 2000. A diverse fauna of Neuropterodea in amber from the Cretaceous of New Jersey. In Grimaldi, D. A. (ed.). Studies on Fossil in Amber, with Particular Reference to the Cretaceous of New Jersey. Backhuys Publishers, Leiden: pp. 259-303.

Grimaldi, D. A. \& Engel, M. S. 2005. Evolution of the Insects. Cambridge University Press, Cambridge, UK.

Handschin, E. 1955. Los insectos de las Islas Juan Femandez. 15. Neuroptera. - Revista Chilena de Entomologia 4: 3-20.

Hoffman, K. M. 2002. Family Mantispidae. In Penny, N. D. (ed.). A Guide to the lacewings (Neuroptera) of Costa Rica. - Proceedings of the California Academy of Sciences 53: 251-275, 419-432.

Kimmins, D. E. 1950. A brachypterous coniopterygid (Order Neuroptera) from Mt. Ruwenzori, Uganda. - Annals and Magazine of Natural History (ser. 12) 3: 166-171.

Kristensen, N. P. 1991. Phylogeny of extant hexapods In Naumann, I. D. (ed.). The Insects of Australia. A Textbook for Students and Research Workers. Vol. 1. 2nd Ed. Melbourne University Press, Carlton: pp. $125-140$.

Lambkin, K. J. 1986. A revision of the Australian Mantispidae (Insecta: Neuroptera) with a contribution to the classification of the family I. General and Drepanicinae. - Australian Journal of Zoology (Supplementary Series) 116: 1-142.

Linnaeus, C. 1758. Systema Natura per Regna Tria Naturae Secundum Classes, Ordines, Genera, Species, cum Characteribus, Differentiis, Synonymis, Locis. 10th Ed. Laurentius Salvius, Holmiae.

MacLeod, E. G. 1960. Sexual differences in the proportions of twowinged and four-winged individuals of Psectra diptera (Burmeister), together with five new records (Neuroptera: Hemerobiidae). - Entomological News 71: 231-236.

Makarkin, V. N. 1990. Novye setchatokrylye (Neuroptera) iz verkhnego mela Azii. In Akimov, I. A. (ed.). Novosti Faunistiki i Sistematiki. Naukova Dumka, Kiev: pp. 63-68.

Makarkin, V. N. 1997. Fossil Neuroptera of the Lower Cretaceous of Baisa, East Siberia. Part 5. Mantispidae. - Russian Entomological Journal 5 (for 1996): 91-93.

Makarkin, V. N. 1999. Fossil Neuroptera from the Lower Cretaceous of Baisa, East Siberia. Part 6. Mesithonidae. - Neues Jahrbuch für Geologie und Paläontologie Monatshefte 1999 (12): 705-712.

Makarkin, V. N. \& Kupryjanowicz, J. 2010. A new mantispid-like species of Rhachiberothinae from Baltic amber (Neuroptera, Berothidae), with a critical review of the fossil record of the subfamily. Acta Geologica Sinica 84: 655-664

Makarkin, V. N., Ren Dong \& Yang Qiang 2011. Two new species of Sinosmylites Hong (Neuroptera: Berothidae) from the Middle Jurassic of China, with notes on Mesoberothidae. - ZooKeys 130: 199-215.

Makarkin, V. N., Yang Qiang, Peng Yuanyuan \& Ren Dong 2012. A comparative overview of the neuropteran assemblage of the Lower Cretaceous Yixian Formation (China), with description of a new genus of Psychopsidae (Insecta: Neuroptera). - Cretaceous Research 35: 57-68

Matsuda, R. 1970. Morphology and evolution of the insect thorax. Memoirs of the Entomological Society of Canada 76: 1-431.

McKellar, R. C. \& Engel, M. S. 2009. A new thorny lacewing (Neuroptera: Rhachiberothidae) from Canadian Cretaceous amber. Journal of the Kansas Entomological Society 82: 114-121.

Meinander, M. 1972. A revision of the family Coniopterygidae (Planipennia). - Acta Zoologica Fennica 136: 1-357.

Nel, A. 1989. Deux nouveaux Mantispidae (Planipennia) fossiles de l'Oligocene du sud-est de la France. - Neuroptera International 5 (for 1988): 103-109. 
Nel, A., Perrichot, V., Azar, D. \& Neraudeau, D. 2005. New Rhachiberothidae (Insecta: Neuroptera) in Early Cretaceous and Early Eocene ambers from France and Lebanon. - Neues Jahrbuch für Geologie und Paläontologie Abhandlungen 235: 51-85.

Ohl, M. 2004. Annotated catalog of the Mantispidae of the world (Neuroptera). - Contributions on Entomology, International 5 (3): [ii] + 131-262.

Ohl, M. 2011. Aboard a spider - a complex developmental strategy fossilized in amber. - Naturwissenschaften 98: 453-456.

Oswald, J. D. 1993. Revision and cladistic analysis of the world genera of the family Hemerobiidae (Insecta: Neuroptera). - Journal of the New York Entomological Society 101: 143-299.

Oswald, J. D. 1996. A new brachypterous Nusulala species from Costa Rica, with comments on the evolution of flightlessness in brown lacewings (Neuroptera: Hemerobiidae). - Systematic Entomology 21: $343-352$.

Panfilov, D. V. 1980. Novye predstaviteli setcharokrylykh (Neuroptera) iz yury Karatau. In Dolin, V. G., Panfilov, D. V., Ponomarenko, A. G. \& Pritykina, L. N. Iskopaemye Nasekomye Mezozoya. Naukova Dumka, Kiev: pp. 82-111, pls 8-15.

Pantaleoni, R. A. \& Letardi, A. 1996. A remarkable brachypterous female of Dilaridae (Dilar parthenopaeus Costa ?) (Neuroptera) In XX International Congress of Entomology. Proceedings. Firenze, Italy, August 25-31 1996: pp. 1-242.

Penny, N. D. 1982. Review of the generic level classification of New World Mantispidae (Neuroptera). - Acta Amazonica 12: 209-223.

Penny, N. D. 1996. A remarkable new genus and species of Ithonidae from Honduras (Neuroptera). - Journal of the Kansas Entomological Society 69: 81-86.

Penny, N. D. \& Strum, H. 1984. A flightless brown lacewing from Colombia. - Spixiana 7: 19-22.

Petrulevicius, J. F., Azar, D. \& Nel, A. 2010. A new thorny lacewing (Insecta: Neuroptera: Rhachiberothidae) from the Early Cretaceous amber of Lebanon. - Acta Geologica China 84: 828-833.

Pohl, H., Beutel, R. G. \& Kinzelbach, R. 2005. Protoxenidae fam. nov. ( Insecta, Strepsiptera) from Baltic amber - a 'missing link' in strepsipteran phylogeny. - Zoologica Scripta 34: 57-69.

Poinar, G. O., Jr. 2006. Feroseta priscus (Neuroptera: Mantispidae), a new genus and species of mantidflies in Dominican amber. - Proceedings of the Entomological Society of Washington 108: 411-417.

Poinar, G. O., Jr. \& Buckley, R. 2011. Doratomantispa burmanica n. gen., n. sp. (Neuroptera: Mantispidae), a new genus of mantidflies in Burmese amber. - Historical Biology 23: 169-176.

Pringle, J. W. S. 1948. The gyroscopic mechanism of the halteres of Diptera. - Philosophical Transactions of the Royal Society of London B233: 347-384.

Ren Dong \& Guo Ziguang 1996. On the new fossil genera and species of Neuroptera (Insecta) from the Late Jurassic of northeast China. - Acta Zootaxonomica Sinica 21: 461-479.

Sinitshenkova, N. D. 2002. Superorder Dictyoneuridea Handlirsch, 1906 (= Palaeodictyopteroidea) In Rasnitsyn, A. P. \& Quicke, D. L. J. (eds). History of Insects. Kluwer Academic Publishers, Dordrecht: pp. 115-125.

Snodgrass, R. E. 1935. Principles of Insect Morphology. McGraw-Hill Book Co., New York.
Swisher III, C. C., Wang Xiolin, Zhou Zhonghe, Wang Yuanqing, Jin Fan, Zhang Jiangyong, Xu Xing, Zhang Fucheng \& Wang Yuan 2002. Further support for a Cretaceous age for the feathered-dinosaur beds of Liaoning, China: new 40Ar/39Ar dating of the Yixian and Tuchengzi Formations. - Chinese Science Bulletin 47: $135-138$.

Swisher III, C. C., Wang Yuanqing, Wang Xiaolin, Xu Xing \& Wang Yuan 1999. Cretaceous age for the feathered dinosaurs of Liaoning, China. - Nature 400: 58-61.

Tauber, C. A., Tauber, M. J. \& Giffin, J. G. 2007. Flightless Hawaiian Hemerobiidae (Neuroptera): Comparative morphology and biology of a brachypterous species, its macropterous relative and intermediate forms. - European Journal of Entomology 104: 787800 .

Tjeder B. 1959. Neuroptera-Planipennia. The Lace-wings of Southern Africa. 2. Family Berothidae. In Hanström, B., Brinck, P. \& Rudebec, F. (eds). South African Animal Life. Results of the Lund University Expedition in 1950-1951. Vol. 6. Almqvist \& Wiksell, Stockholm: pp. 256-314.

Wang Songshan, Hu Huaguang, Li Peixian \& Wang Yuanqing 2001a. Further discussion on geologic age of Sihetun vertebrate assemblage in western Liaoning, China: Evidence from Ar-Ar dating. - Acta Petrologica Sinica 17: 663-668. [In Chinese, English abstract].

Wang Songshan, Wang Yuanqing, Hu Huaguang \& Li Huimin 2001b. The existing time of Sihetun vertebrate in western Liaoning, China: evidence from U-Pb dating of zircon. - Chinese Science Bulletin 46: 779-782.

Wang Xiaolin \& Zhou Zhonghe 2008. Mesozoic Pompei. In Chang Meemann (ed.). The Jehol Biota. Academic Press, Elsevier, Amsterdam: pp. 19-35.

Wedmann, S. \& Makarkin, V. N. 2007. A new genus of Mantispidae (Insecta: Neuroptera) from the Eocene of Germany, with a review of the fossil record and palaeobiogeography of the family. - Zoological Journal of the Linnean Society 149: 701-716.

Whalley, P. E. S. 1983. Fera venatrix gen. and sp. n. (Mantispidae) from amber in Britain. - Neuroptera International 2: 229-233.

Winterton, S. L., Hardy, N. B. \& Wiegmann, B. M. 2010. On wings of lace: phylogeny and Bayesian divergence time estimates of Neuropterida (Insecta) based on morphological and molecular data. - Systematic Entomology 25: 349-378.

Wootton, R. J. 2003. Wings. In Resh, V. H. \& Carde, V. H. (eds). Encyclopedia of Insects. Academic Press, London: pp. 11861192.

Yang Wei, Li Shuguang \& Jiang Baoyu 2007. New evidence for Cretaceous age of the feathered dinosaurs of Liaoning: zircon U-Pb SHRIMP dating of the Yixian Formation in Sihetun, northeast China. - Cretaceous Research 28: 177-182.

Zimmerman E. C. 1939. Studies of Hawaiian Neuroptera. - Proceedings of the Hawaiian Entomological Society 10: 487-510.

Zimmerman, E. C. 1946. A remarkable new Pseudopsectra from Maui (Neuroptera: Hemerobiidae). - Proceedings of the Hawaiian Entomological Society 12: 559-660.

Zimmerman, E. C. 1957. Order Neuroptera. In Insects of Hawaii. Vol. 6. University of Hawaii Press, Honolulu: pp. 19-169. 